\title{
ENHANCED OIL RECOVERY METHODS ON OFFSHORE FIELDS IN THE LIGHT OF WORLD LITERATURE
}

\section{INTRODUCTION}

Since the 1959 up to 2010 more than 600 Enhanced Oil Recovery (EOR) projects were implemented worldwide, and according to the report of "The Oil and Gas Journal" there were exactly 652 projects. However, only a small fraction of the hydrocarbon resources is produced by using EOR methods. The following diagram (Fig.1) is a classification of a global EOR projects broken down by category.

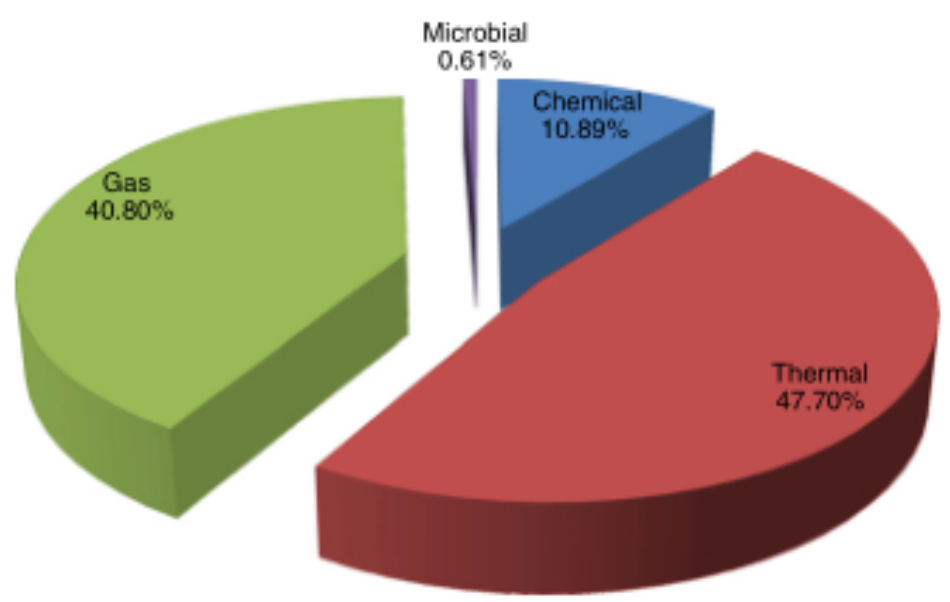

Fig. 1. World EOR project categories in 1959-2010(Al. Adasani, 2011)

* AGH University of Science and Technology, Faculty of Drilling, Oil and Gas, Krakow, Poland 
The most common are thermal methods, in particular steam injection, and gas injectionsuch as miscible $\mathrm{CO}_{2}$ flooding. The current global trend in EOR methods shows that more and more important role will be played by chemical methods such as polymer and surfactant flooding, polymer gels and injection of a modified conventional water (with low salinity or chemical additives) (Al. Adasani, 2011).

\section{WORLDWIDE APPLICATIONS OF EOR}

Number of currently producing fields using EOR methods in the world outside the United States, Canada, Norwegian Continental Shelf (NCS) and Poland is shown in table 1. Most of them are successful in hydrocarbon recovery except the four projects using steam (one in Venezuela and three in Trinidad). Only two projects are in other rock than sandstone one project in dolomite and one in limestone. In Bohai Bay in China three successful polymer EOR projects on offshore heavy oil fields were developed until 2010. Additional projects of steam injection in Germany and combustion in Brazil are currently in the planning phase (Kottungal, 2013).

Table 1

Producing EOR projects outside USA, Canada, NCS and Poland(Kottungal, 2013)

\begin{tabular}{|l|l|c|}
\hline \multicolumn{2}{|c|}{ EOR Technology } & Projects \\
\hline \multirow{4}{*}{ Gas injection } & Miscible $\mathrm{CO}_{2}$ & 2 \\
\cline { 2 - 3 } & Immiscible $\mathrm{CO}_{2}$ & 7 \\
\cline { 2 - 3 } & Miscible hydrocarbons & 3 \\
\hline Biological methods & Microbial (MEOR) & 1 \\
\hline \multirow{3}{*}{ Chemical methods } & Surfactant flooding & 1 \\
\cline { 2 - 3 } & Alkaline and gel & 3 \\
\cline { 2 - 3 } & Polymer flooding & 72 \\
\hline Thermal methods & Steam & $\mathbf{9 0}$ \\
\hline Total & & \\
\hline
\end{tabular}

\section{EOR IN USAAND CANADA}

The oil industry in the U.S. has more than 40 years of operational experience with the technology of $\mathrm{CO}_{2}$-EOR (first operations began in west Texas in 1972). Currently by using carbon dioxide is being produced nearly 300,000 barrels of oil per day (which represents $6 \%$ of the total daily oil production in the U.S.). It is estimated that using current technologies of $\mathrm{CO}_{2}$-EOR it can be produced an additional 26 to 61 billion barrels of oil and using next-generation technology (i.e. increasing the amount of injected $\mathrm{CO}_{2}$, optimizing design 
and placement of wells and through use of chemical additives to reduce the minimum miscible pressure) it would increase the economically recoverable resources more than twice (Greenwald, 2012). Figure 2 shows the production in $\mathrm{CO}_{2}$-EOR technology in the United States.

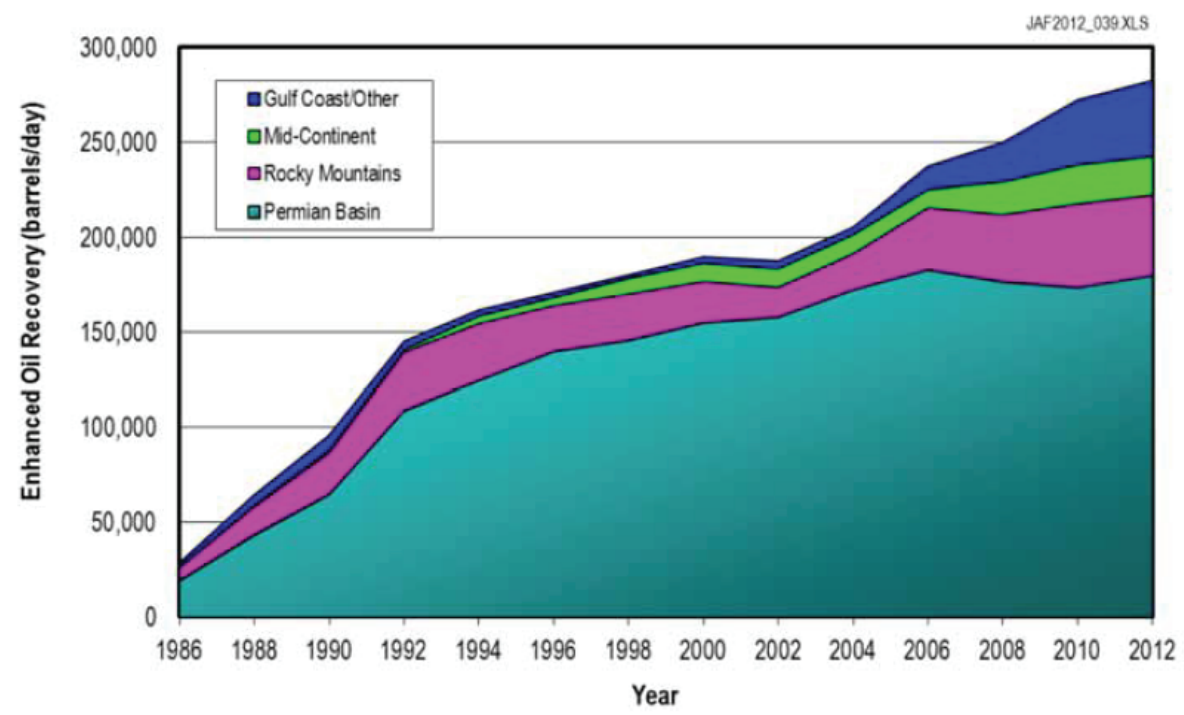

Fig. 2. $\mathrm{CO}_{2}$-EOR production in USA in years 1986-2012 (DiPietro, 2013)

In 2010 in the United States 114 gas injection projects were implemented and 124 projects in 2012: miscible (107 and 115 projects accordingly) and immiscible (7 and 9 projects accordingly). This increased total oil production by 5\% in 2010 and $4.5 \%$ in 2012 (DiPietro, 2013).

Seven projectsof miscible gas injection and one acid gas injection are carried out in Canada. The most famous is the Weyburn field where, thanks to $\mathrm{CO}_{2}$ injections, over $65 \%$ growth in oil production was achieved. Carbon dioxide used there is anthropogenic, purchased from a nearby refinery (ARI, 2010).

Due to the availability of natural carbon dioxide in America projects related to carbon dioxide are very popular, but this technology despite its effectiveness is not yet used in Europe.

Table 2 shows the number of currently producing EOR projects in the United States and Canada. With all the projects only seven were found to be negative, the other gave a positive result, and in a few cases, it is too early to evaluate the outcome. In contrast to the rest of the world a large number of projects are in carbonate rocks, mainly these are: miscible $\mathrm{CO}_{2}$ injection injections (47 in dolomite, 21 in limestone), miscible hydrocarbon injections (16 in dolomite, 4 in limestone) and combustion processes (11 in dolomite). In 2012-2014 new projects are planned - six immiscible $\mathrm{CO}_{2}$ injections, a polymer injection and two steam injections (Kottungal, 2013). 
Table 2

Producing EOR projects in USA and Canada (Kottungal, 2013).

\begin{tabular}{|l|l|c|}
\hline \multicolumn{1}{|c|}{ Technology } & Projects \\
\hline \multirow{5}{*}{ Gas injection } & $\mathrm{CO}_{2}$ miscible & 118 \\
\cline { 2 - 3 } & $\mathrm{CO}_{2}$ immiscible & 9 \\
\cline { 2 - 3 } & Acid gas miscible & 1 \\
\cline { 2 - 3 } & Hydrocarbon miscible & 32 \\
\cline { 2 - 3 } & Hydrocarbon immiscible & 1 \\
\cline { 2 - 3 } & Nitrogen & 4 \\
\hline Chemical methods & Polymer, surfactant & 58 \\
\hline \multirow{5}{*}{ Thermal methods } & Steam & 2 \\
\cline { 2 - 3 } & Hot water & $\mathbf{2 4 2}$ \\
\cline { 2 - 3 } & Combustion & \\
\hline Total & & 24 \\
\hline
\end{tabular}

\section{EOR ON NORWEGIAN CONTINENTALSHELF}

The experience of EOR methods on the Norwegian Continental Shelf are small, six technologies were used during the 19 projects until 2005 (miscible gas injection, miscible and immiscible water alternating gas (WAG), simultaneous WAG (SWAG), foam assisted WAG (FAWAG) and microbiological methods (MEOR). Projects have been implemented mostly successfully, and the best results were with WAG method, which is also the most refined of all. It is because waterflooding often give effective oil recovery and WAG can be used effectively to displace residual oil left in the reservoir. Incjectivity problems connected with WAG, SWAG and FAWAG methods could be reduced by using MEOR processes, which are also helpful with heterogeneous reservoir. In Norwegian part of the shelf there were 12 projects, 6 in English part and one in Danish. The biggest contractor company was Statoil - seven projects. All reservoirs were producing light oil (32 to 41 API degrees) and apart from the Ekofisk reservoir, which is composed of fractured limestone of low-permeable matrix, others are in sandstone formations with a high permeability channels (Awan et al., 2008). Table 3 shows a detailed statistics of 19 EOR projects until 2005.

Currently, most of the deposits in Norway produces hydrocarbons with primary or secondary methods, only 8 on reservoirs third methods are used. Table 4 is a summary of currently producing fields in Norway and methods used. WAG method is used on reservoirs: Gullfaks, Oseberg, Oseberg East, Snorre, Ula, Varg, Veslefrikk and Visund. In the near future it is planned to apply the WAG method on a Brage reservoir, MEOR method on Norne field and modified water with silicone gels on Snorre (FactPages, 2013). 
Table 3

EOR projects on NCS until 2005 (Awan et al., 2008)

\begin{tabular}{|c|c|c|c|c|c|c|c|}
\hline $\begin{array}{l}\text { EOR } \\
\text { method }\end{array}$ & $\begin{array}{l}\text { Field name (start } \\
\text { production) }\end{array}$ & $\begin{array}{l}\text { Type of } \\
\text { rock }\end{array}$ & $\begin{array}{l}\text { Temp. } \\
{\left[{ }^{\circ} \mathrm{C}\right]}\end{array}$ & $\begin{array}{c}\text { Pressure } \\
\text { [bar] }\end{array}$ & $\begin{array}{l}\text { Previous } \\
\text { method }\end{array}$ & $\begin{array}{c}\text { Start of } \\
\text { EOR }\end{array}$ & $\begin{array}{c}\text { Result of } \\
\text { EOR }\end{array}$ \\
\hline \multirow{6}{*}{$\begin{array}{l}\text { Miscible } \\
\text { gas } \\
\text { injection }\end{array}$} & Ekofisk (1971) & Limestone & 131 & 491 & Primary & 1975 & Succ. \\
\hline & Beryl (1976) & Sandstone & & 337 & Primary & 1977 & Succ. \\
\hline & Statfjord (1979) & Sandstone & 99 & 404 & Primary & 1979 & Succ. \\
\hline & Brent (1976) & Sandstone & 103 & 423 & WF & 1981 & Succ. \\
\hline & Alwyn North (1987) & Sandstone & 113 & 450 & WF & 1999 & Succ. \\
\hline & $\begin{array}{c}\text { Smorbukk South } \\
\text { (1999) }\end{array}$ & Sandstone & 140 & 405 & Primary & 1999 & Succ. \\
\hline \multirow{3}{*}{$\begin{array}{l}\text { Miscible } \\
\text { WAG }\end{array}$} & Snome (1992) & Sandstone & 90 & 383 & WF & 1994 & Succ. \\
\hline & South Brae (1963) & Sandstone & 123 & 492 & WF & 1994 & Succ. \\
\hline & Magnus (1963) & Sandstone & 116 & 459 & WF & 2002 & Succ. \\
\hline \multirow{6}{*}{$\begin{array}{c}\text { Immiscible } \\
\text { WAG }\end{array}$} & Thisle (1978) & Sandstone & 102 & 418 & WF & 1980 & Succ. \\
\hline & Gulfaks (1966) & Sandstone & 74 & 310 & WF & 1991 & Succ. \\
\hline & Brage (1993) & Sandstone & 87,5 & 215 & WF & 1994 & Succ. \\
\hline & Ekofisk (1971) & Limestone & 131 & 491 & $\begin{array}{c}\text { WF and gas } \\
\text { injection }\end{array}$ & 1996 & Unsucc. \\
\hline & Statfjord (1979) & Sandstone & 92 & 385 & WF & 1997 & Succ. \\
\hline & OsebergOst (1999) & Sandstone & 113 & 319 & WF & 1999 & Succ. \\
\hline SWAG & Siri (1999) & Sandstone & & 232 & Primary & 1999 & Succ. \\
\hline \multirow{2}{*}{ FAWAG } & Snorre CFB (1992) & Sandstone & 90 & 380 & WAG & 1997 & $?$ \\
\hline & Snorre WFB (1992) & Sandstone & 90 & 380 & WAG & 1999 & Succ. \\
\hline MEOR & Norne (1997) & Sandstone & 98 & 273 & $\begin{array}{l}\text { WF and gas } \\
\text { injection }\end{array}$ & - & $?$ \\
\hline
\end{tabular}

Abbreviations: WF - Waterflooding, Succ. - Successful, Unsucc. - Unsuccessful

Table 4

Methods used in currently producing fields on NCS (FactPages, 2013).

\begin{tabular}{|l|c|}
\hline \multicolumn{1}{|c|}{ Methods } & Fields \\
\hline Primary & $\mathbf{3 8}$ \\
\hline Secondary & $\mathbf{3 2}$ \\
\hline Gas injection & 5 \\
\hline Water injection & 21 \\
\hline Water and gas injection & 6 \\
\hline EOR & $\mathbf{8}$ \\
\hline WAG & 8 \\
\hline Total & $\mathbf{7 8}$ \\
\hline
\end{tabular}




\section{EOR IN POLAND}

In Poland, the oil is extracted mainly with primary methods and experience in the application of EOR methods is small - in the years 1932-1987, only 26 projects were carried out. Currently, gas is injected into theBorzęcinreservoir, which can be seen as the third method, although the main objective is sour gas storage which is formed during gas desulfurization (Rychlicki, 2010).

Below are listedall EOR projects performed in Poland (Rychlicki, 2010):

- Air injection - 13 projects (five successful).

- Gas injection - 3 successful projects.

- Microbiological Method - 8 projects (two successful).

- Water and gas injection - 2 successful projects.

- Currently acid gas injection tofields: Borzęcin and KamienPomorski.

Research conducted at AGH in 2007-2009 to test the possibility of increasing the efficiency of oil extraction from the Carpathian reservoirs shows, that the use of carbon dioxide is a good EOR method. During the simplified computer simulations, increase in production was obtained from 4 to $10 \%$ of the initial geological reserves in the reservoir. It was also suggested to conduct a thorough laboratory experiments and update the geological model, for a deeper analysis of the phenomena occurring during the process of $\mathrm{CO}_{2}$ injection.

\section{CARBON DIOXIDE- ENHANCED OIL RECOVERY $\left(\mathrm{CO}_{2}-\mathrm{EOR}\right)$}

There are currently two methods of injecting carbon dioxide into the reservoir: in the form of gas or water-based. The firststrategy is the conventional continuous $\mathrm{CO}_{2}$ injection or with water (WAG). These methods require a large amount of the available carbon dioxide, which is injected under supercritical conditions, above its critical pressure and temperature (7.39 $\mathrm{MPa}$ and $31.1^{\circ} \mathrm{C}$ ). The second way is the injection ofCO in water-based form, where carbon dioxide is dissolved in water or saline prior to injection, and then transported through reservoir in water (Kechut et al., 2011).

$\mathrm{CO}_{2}$ injection in the form of gas can be divided into two processes (ARI, 2010):

- Miscible - multiple contact process in which the exchange takes place between the injected carbon dioxide and oil in the reservoir. During this process $\mathrm{CO}_{2}$ vaporizes the lighter oil fractions into the carbon dioxide phase, and condenses into the oil phase. This leads to the two fluids reservoir which are miscible, with lower viscosity and surface tension. The main objective of the miscible process is to improve the flow and reduce the residual oil remaining after the process of waterflooding. Miscible process is currently most used $\mathrm{CO}_{2}$-EOR. Figure 3 shows a diagram of the process. 
- Immiscible - this process occurs when reservoir pressure is low or oil components are heavier. The main mechanisms during the immiscible process are:

1. Oil phase swelling, when oil becomes saturated with $\mathrm{CO}_{2}$.

2. Viscosity reduction of oil and the mixture of carbon dioxide.

3. Extraction of lighter hydrocarbons into $\mathrm{CO}_{2}$ phase.

4. Creation of additional reservoir pressure.

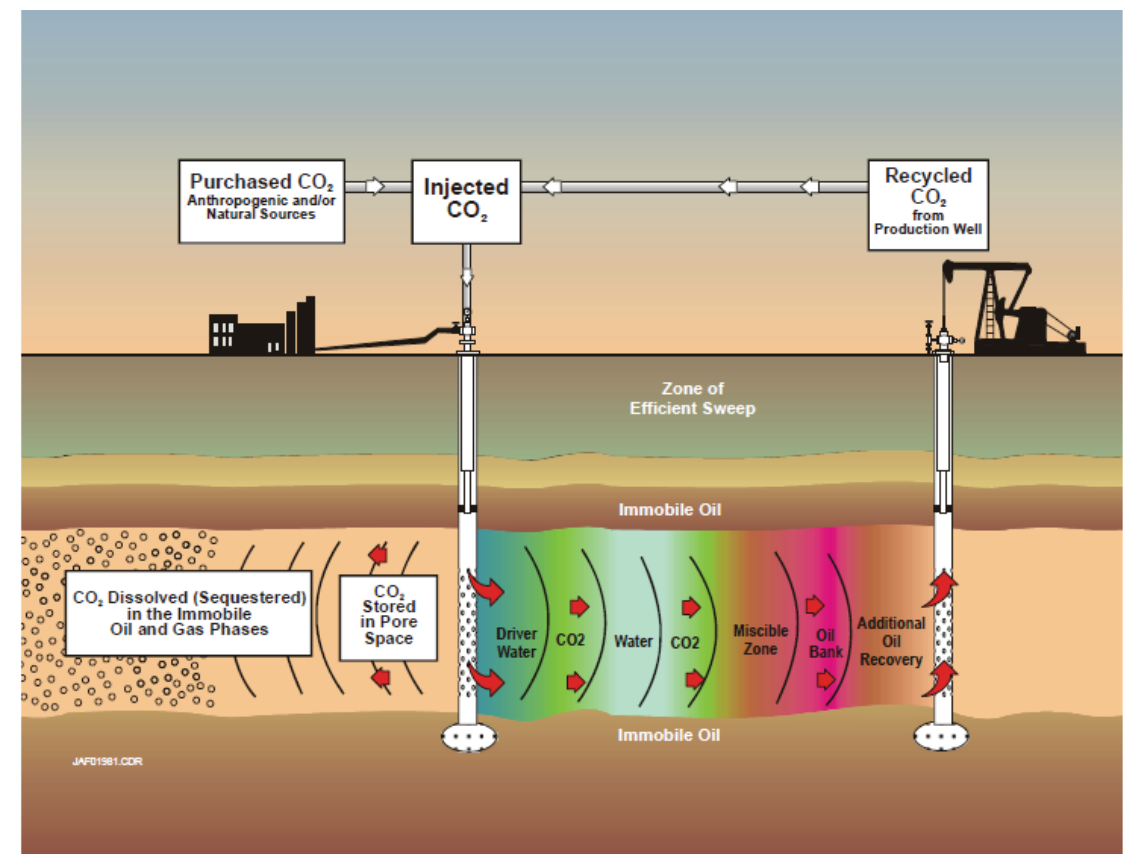

Fig. 3. Miscible $\mathrm{CO}_{2}$-EOR process (ARI, 2010)

Carbon dioxide would be used more often if not its poor accessibility. Unfortunately in many cases, it needs to be purchased at a high price, and transported, which reduces its attractiveness. In addition to the economic and logistic constraints there are also ones associated with the process mechanisms in the reservoir. Since the $\mathrm{CO}_{2}$ is injected under supercritical conditions, its viscosity is less than water, and most types of crude oils, which can lead to conformance and mobility issues and the formation of preferential paths in the rock (Talebian, 2013). These mechanisms are shown in the following figure 4.

Achieving miscibility during a single contact is also a difficult task during the injection of carbon dioxide due to the complex nature of crude oils. At a certain distance of the front multiple-contact miscibility can be achieved, but at the expense of leaving the heavier components of oil behind the front. These fractions may reduce the overall permeability of a rock where carbon dioxide already has passed (Talebian, 2013) 


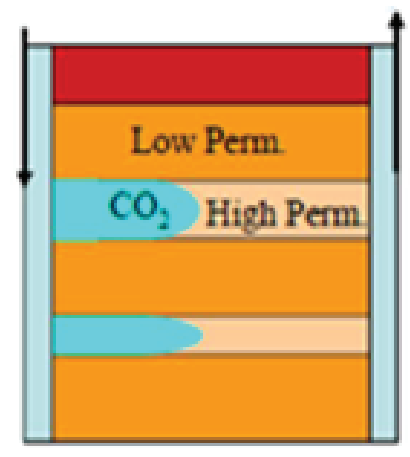

A

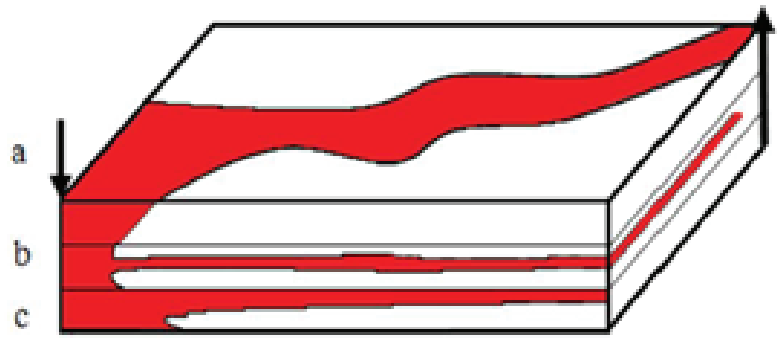

B

Fig. 4. A - Conformance issue, B - mobility issues: (a) poor area sweep, (b) gas channelling,

(c) gravity override (Talebian, 2013)

\section{WATER ALTERNATE GAS (WAG)}

WAG injection method is used since the early 60 s of the last century. Different variations and modifications of this technique were created. For each reservoir, however, separatescreening, testing and computer simulation, should be carried out in order to find the optimal strategy, since it depends on many factors. These include the heterogeneity of the reservoir, injection techniques, WAG parameters, miscibility conditions and different patterns of injection wells localization (Rogers and Grigg, 2001). WAG method can be used during miscible and immiscible processes.

In laboratory studies and computer simulations many varieties of WAG methods have been tested such as:

- SWAG (Simultaneous WAG).

- $\mathrm{WACO}_{2}$ (Water Alternate $\mathrm{CO}_{2}$ ).

- $\mathrm{SWACO}_{2}\left(\right.$ Simultaneous Water Alternate $\left.\mathrm{CO}_{2}\right)$.

- FAWAG (Foam Assisted WAG).

- GASWAG (Gravity Assisted Simultaneous Water and Gas Injection).

GASWAG technique is based on controlling the injection by turning off inactive perforation, increasing the number of wells and the selective control of gas injection points (bottom of reservoir) and water (top of reservoir) (Forrest et al., 2009). A similar technique was used in Kuwait, where gas and water was injected selectively, thus preventing gravity segregation effects (Al- Ghanim et al., 2010). In most cases, modification of the conventional water and gas injection gave positive results for additional oil recovery.

One of the solutions to improve the efficiency of displacing reservoir fluids is to increase the viscosity of injected fluid and reducing mobility of $\mathrm{CO}_{2}$. Currentlyin petroleum industry WAG technology is used for $\mathrm{CO}_{2}$ mobility control, and various mechanical methods (cement, 
packers, well control, infield drilling and horizontal wells) in order to improve $\mathrm{CO}_{2}$ flood conformance (Enicket al., 2012).

Reducing the salinity of the water (thereby increasing the solubility of carbon dioxide in the water) during the application of the $\mathrm{WACO}_{2}$ and $\mathrm{SWACO}_{2}$ methods gave better results up to $18 \%$ of additional oil production. These results were obtained during laboratory experiments conducted in heterogeneous carbonate rocks (Aleidan and Mamora, 2010)

Despite the different varieties, WAG method is also imperfect, and in particular in the heterogeneous reservoirsviscous instabilities and gravity segregation problems occurs. The balance between the amount of injected water and gas must be achieved. Too large amount of gas would lead to the viscous instabilities and gravity segregation effects, while too much water can lead to entrapment of oil by water. The addition of foam in the water has been suggested as a way to reduce the mobility of the gas phase. In order to further improve $\mathrm{CO}_{2} \mathrm{EOR}$ technology chemical additives are used (polymers, gels, $\mathrm{CO}_{2}$ foam). Research still continues on in this field (Talebian, 2013).

\section{LOW SALINITY WATER INJECTION}

Waterflooding is the main secondary method used in the oil industry to maintain reservoir pressure. As a rule, produced water is injected during operation. However, laboratory tests and operational experience has shown that a much better result in the ultimate recovery of oil can be obtained using low salinity water. This method started to be popular when during experiments it was shown an increase in oil production after reducing the salinity from $15,000 \mathrm{ppm}$ to $100 \mathrm{ppm}$ in the injected brine. In the last decade we have seen a large number of laboratory experiments designed to understand the mechanisms of the injection water with low salinity, but scientists are still trying to determine the final version (Zhang, Morrow, 2006).

Four possible hypotheses have been proposed:

1. The reduction of permeability during migration of clay fine (Tang, 1999).

2. Temporary increase $\mathrm{pH}$ in the reaction between the clay and the low salinity water (Austad et al., 2010).

3. Multi-composite ion exchange between the surface of the clay mineral and the injected brine (Lager et al., 2008).

4. Modification of wettability, as a result of the migration of clays (Tang, 1999).

The literature shows that the most frequently stated reason for increased oil recovery during low salinity water injection is the change of wettability of rocks from a neutral or oilwet to water-wet. Also an important role has clay material, and for that reason the study of carbonate rocks was initially ignored because they lack clays.

In 2012, British Department of Energy (DECC) developed a report on the low salinityand summarised the current state of research and experience. 
The main conclusions from the report are (Hughes, 2012):

- The injection of low salinity water is immature technology, without any major field applications, but large oil companies are very interested in its development.

- Laboratory tests show a significantly better effect of low salinity water injection in the secondary mode than the tertiary, especially when appliedto the British Continental Shelf.

- Implementing the injection of low salinity water should not cause any operational problems.Currently reservoirs on the continental shelf have injected from 60 to $75 \%$ sea water in the pores of rock, so produced water management is crucial.

- The role of microbes during low salinity water injection is rarelymentioned in the literature. But bacteria's influence should be examined in laboratory.

- Availabilityof low salinity water in reservoir can make the other chemical EOR methods more effective and less expensive by reducing the amount of chemicals needed.

Currently, there is one big pilot project in Alaska by BP, where low salinity water is used as a secondary method. On the Norwegian Continental Shelf, some fields are taken into account with possibility of using on them this technology, these are Heidrun, Snorre, Gullfaks, Froy and Varg fields. In the computer simulation software, both commercial and belonging to the operators, the appropriate techniques for modelling the effects of low salinity water are already implemented, though still imperfect, but can they be used to assess the overall efficiency of the process (Hughes, 2012).

\section{CARBONATED WATER INJECTION (CWI)}

Conventional $\mathrm{CO}_{2}$ flooding is not often efficient process due to the difference in viscosity between $\mathrm{CO}_{2}$ and reservoir fluids. Different strategies such as WAG injection or $\mathrm{SWACO}_{2}$ were suggested in order to minimize this problem. Another alternative technique is to use injection water enriched with $\mathrm{CO}_{2}$. Carbon dioxide is dissolved in water, thus reducing the problem of gravity segregation and the poor sweep efficiency, which are characteristic of typical $\mathrm{CO}_{2}$ flooding. Dissolution of $\mathrm{CO}_{2}$ in the water, increases her viscosity and density, which positively influences the extraction of oil. An additional advantage is the ability to increase the amount of injected carbon dioxide and this is an important point for optimization ofincreased oil production and the simultaneous storage of carbon(Sohrabi et al., 2009). Figure 5 shows solubility of $\mathrm{CO}_{2}$ in water.

CWI was used for the first time as an additional process together with waterflooding in 1962 in the USA, but for many years there have been no reports on its usage. In 2011 a laboratory experiments and numerical simulation was conducted at Heriot-Watt University. It was found that the CWI method significantly increases production of crude oil compared to conventional injection of the water (more than 5\% increase). CWI technology shows also good prospects to carbon storage. In experiment, about $50 \%$ of the injected gaswas stored in the sample.But the best results were obtained when water with dissolved carbon dioxide was 
injected before conventional waterflooding. In theexperimentwere observed different mechanism with light and high viscosity crude oil.Swelling was much more significant with light oil, and bigger viscosity reduction was observed with high viscosity oil, but with both fluids study ended with increased oil recovery (Sohrabi et al., 2009).

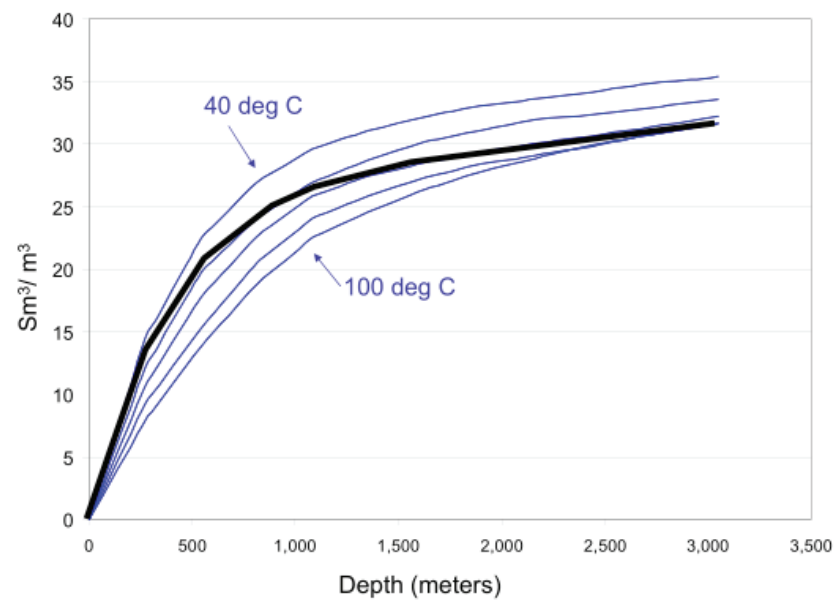

Fig. 5. $\mathrm{CO}_{2}$ solubility in water (Jackson, 2007)

Different research from 2013 shows that the use of CWIas a secondary recovery can increase ultimate oil production by about $19 \%$ as compared to that of conventional water flooding. Experiment was done at various operating pressures (from 0.7 to $10.3 \mathrm{MPa}$ ). It was observed that an increase in operating pressure enhances the oil recovery, it was attributed to higher $\mathrm{CO}_{2}$ solubility in the injected brine. Also significant amount of $\mathrm{CO}_{2}$ was stored at the end of experiment (from $23 \%$ to $36 \%$ of total injected $\mathrm{CO}_{2}$ )(Mosavat andTorabi, 2013).

Features of the injection water with dissolved carbon dioxide (Jackson, 2007):

- Good efficiency of $\mathrm{CO}_{2}$ - important when the purchase cost of carbon dioxide is high and the availability of gas less than forecasted EOR potential.

- Relevant to immiscible injection, less applicable to miscible flooding because of gravity problems.

- Response of reservoir is slower but the ultimate recovery is higher.

\section{CHEMICAL METHODS}

Chemical methods, especially on offshore fields attracted a lot of attention since long time. The recent technological advances in chemical additives increased the number of pilot projects in the world (China, Angola), in particular low salinity water injection technology opens up new possibilities in the application of chemical methods (Alvarado and Manrique, 2013). 
The basic method is the injection of a chemical surfactant (surfactant flooding) which reduces the surface tension between oil and the displacing fluid. The result is an increasedcapillary number, which improves the extraction of residual oil. Alkaline flooding is based on creating surfactants within the reservoir. Surface tension between brine and oil can be reduced, thus increasing the efficiency of microscopic displacement, which increases oil production. Other mechanisms identified during the alkalization of the water in reservoir are the emulsification of the oil and change the wettability of the rock formation. All three mechanisms can influence the microscopic displacement and emulsification may also affect the macroscopic efficiency. Mobility control is an important factor in the alkaline process, as in all EOR processes. It is often necessary to add the polymer in an alkaline solution in order to reduce the tendency to create a viscous instability. The injection of polymer increases the viscosity of the displacing fluid, which provides a better control of the displacement process. Polymers however, are sensitive to salt and other minerals in the water therefore they must be appropriately treated to obtain good properties. Polymers are typically added to water at concentrations ranging from 250 to 2000 parts per million (ppm). Polymers have also been used to alter the permeability of certain reservoirs. They form a gel by crosslinking with other chemicals. The polymer gel, by blocking the high permeability channels, changes the flow direction of the injected fluid in placepreviously discarded (Risbakk, 2013).

The combination of three methods (surfactant, alkaline and polymer flooding) allows for a more efficient process that can be used in different conditions. Creating in-situ surfactant reduces the required amount of chemicals during a single injection process and the combination of ASP (Alkaline, Surfactant and Polymer) gives very low surface tension so that the polymer can better control the displacement effect (Hirasaki et al., 2006).

It is anticipated that the technologies of conventional polymer gels or thermally activated polymers (Bright Water) will beused increasingly in more offshore projects. Both methods allow delayedentry of injected waterinto the pores of the rock, which has been proven in tests for onshore reservoirs such as El Tordillo in Argentina and in the North Sea in Norway. Figure 6 shows the saturation model of the reservoir where is a problem of poor displacement efficiency (blue highlighted area in the southern part of the reservoir). The injected cold water with the mixed polymer, heats to a reservoir temperature and the polymer swells under the influence of temperature, blocking access to the rock pores and reducing the permeability. The result of that is that the injected water in subsequent cycles(without polymer) will be diverted towards lesser swept area (Roussennac and Toschi, 2010).

From all presented EOR methods, water alternating gas (WAG) seems to be most often used and mature technology, with its different varieties it can be applied to most of the offshore fields. Eleven successful WAG projects were developed in Norwegian Continental Shelf until 2005 and eight still continues today. Reduced injectivity problems could be reduced by using microbial (MEOR) method, though there are not many field experiences worldwide. Different mature and efficient EOR technology is miscible gas injection, in USA and Canada, mainly $\mathrm{CO}_{2}$ is injected into the reservoirs. But lack of good sources of $\mathrm{CO}_{2}$ makes it harder to use on offshore fields. 

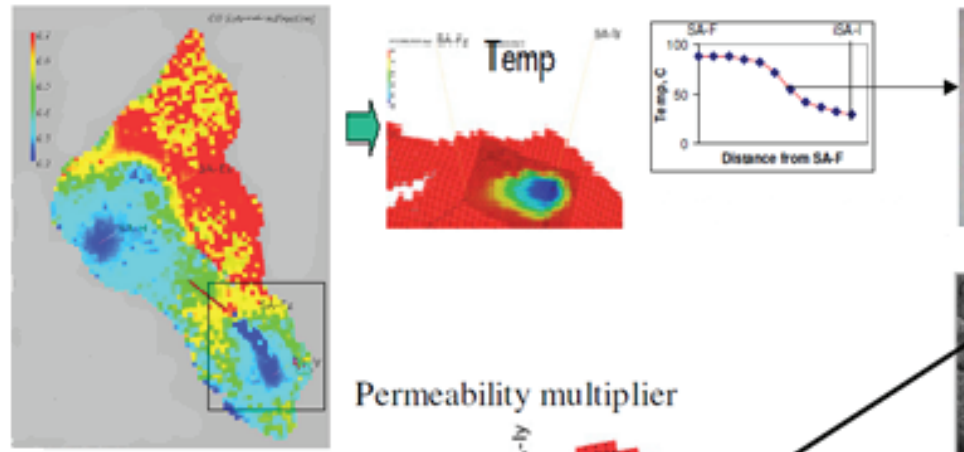

Temp and Time

Permeability multiplier
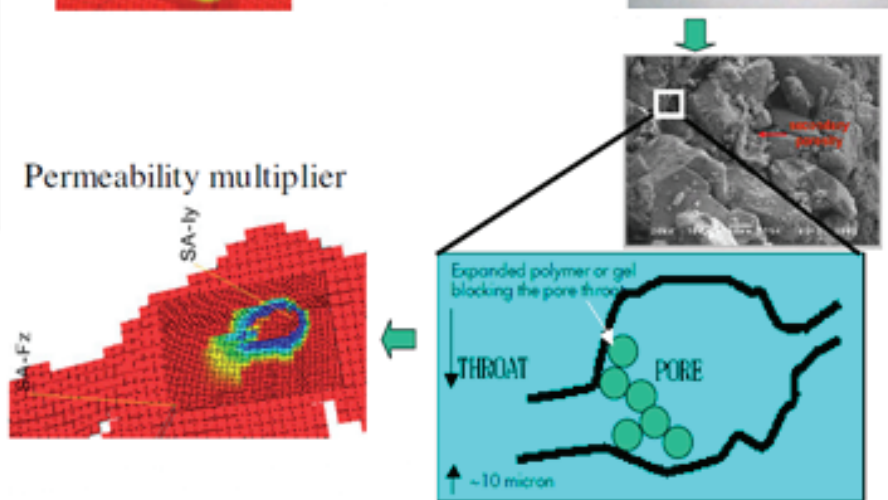

Fig. 6. BrightWaterprocess in Salemafield in Brasil(Roussennac andToschi, 2010).

\section{CONCLUDING REMARKS}

New technologies researched now are low salinity water injection and carbonated water injection. First laboratory studies and field pilot test which are being deployed currently indicate very positive results. More in-depth research is needed to be able to apply them offshore. Also very promising are chemical methods, which in recent years got more and more popular (especially surfactant flooding, polymer flooding and polymer gels).

\section{REFERENCES}

[1] Al Adasani Ahmad, Baojun Bai, Analysis of EOR projects and updated screening criteria, Journal of Petroleum Science and Engineering 79 (2011) 10-24, 2011

[2] Aleidan A., Mamora D.D., SWACO2 and WACO2 Efficiency Improvement in Carbonate Cores by Lowering Water Salinity, CSUG/SPE, 2010

[3] Al-Ghanim W.R., GharbiRidha, AlgharaibMeshal, Designing a Simultaneous Water Alternating Gas Process for Optimizing Oil Recovery, SPE 120375, 2009

[4] Alvarado Vladimir, Manrique Eduardo, Engineering Design Challenges and Opportunities beyond Waterflooding in Offshore Reservoirs, OTC 24105, Houston, USA, 6-9 May, 2013

[5] ARI, Optimization of $\mathrm{CO}_{2}$ Storage in $\mathrm{CO}_{2}$ enhanced Oil Recovery Projects, Advanced Resources International (ARI) USA and Melzer Consulting USA, November 2010 
[6] Austad T., RezaeirDoustAilreza, Puntervold Tina, Chemical Mechanism of Low Salinity Water Flooding in Sandstone Reservoirs, SPE 129767, 2010

[7] Awan A.R., Teogland R., Kleppe J., A Survey of North Sea Enhanced Oil Recovery Projects Initiated During the Years 1975 to 2005, SPE 99546, 2008

[8] DiPietro Phil, Carbon Dioxide Enhanced Oil Recovery in the United States: Snapshot and Forecast, Co2 Enhanced Oil Recovery - Operations In The Permian Basin Conference, March 25-26, 2013.

[9] Enick R.M., Olsen D., Ammer J., Schuller W., mobility and Conformance control for CO2 EOr via Thickeners, foams, and Gels - A literature review of 40 Years of Research and Pilot Tests, SPE 154122, 2012

[10] FactPages, Field Producing, http://factpages.npd.no, 2013

[11] Forrest J.K., Hussain A., Orozco M., Bourge J.P., Bui T., Henson R., Jalaludin J., Samarang Field - Seismic To Simulation redevelopment Evaluation Brings new Life to an Old Oilfield, Offshore Sabah, Malaysia, SPE 13162, 2009

[12] Greenwald Judi, A Diverse Coalition Recommends Incentives to Accelerate Commercial Deployment of EOR Using Captured CO2, CCUS Forum, April 5, 2012.

[13] Hirasaki G.J., Miler, C.A., Pope Gary A., Surfactant Based Enhanced Oil Recovery and Foam Mobility Control, $3^{\text {nd }}$ Annual Technical Report, February 2006

[14] Hughes David, Law Stuart, Pitt Gemma, Low Salinity EOR “State of Play”, Final raport conducted for DECC, Senergy, September 2012

[15] Jackson Geoffre, Carbonated Water Flooding, Carbon Dioxide Management for EOR Workshop, Kuwait, Mai 14-15, 2007.

[16] Kechut Nor Idah, SohrabiMehran, JamiolahmadyMahmoud,Experimental and Numerical Evaluation of Carboanted Water Injection (CWI) for Improved Oil Recovery and CO2 Storage, SPE 143005, 2011Kottungal Lena, "2012 worldwide EOR survey", http://www.ogj.com, 2013

[17] Lager A., Webb K.J., Collins I.R., Richmond D.M., LoSal Enhanced Oil Recovery: Evidence of Enhanced Oil Recovery at the Reservoir Scale, SPE 113976, 2008

[18] Nader Mosavat and FarshidTorabi, Performance of Secondary Carbonated Water Injection in Light Oil Systems, Ind. Eng. Chem. Res., 2013

[19] Risbakk Jan Kare, Synopsis on Enhanced Oil Recovery, PGNiG Upstream International AS, unpublished, 2013

[20] Rogers John D., Grigg Reid B., A literature Analysis of the WAG Injectivity Abnormalities in the CO2 Process, SPE Reservoir Evaluation \& Engineering, October 2001

[21] Roussennac Bruno, ToschiCelso, Brightwater ${ }^{\circledR}$ Trial in Salema Field (Campos Basin, Brazil), SPE 131299, 2010

[22] Rychlicki Stanisław, Możliwości zwiększenia efektywności wydobycia ropy naftowej ze złóż karpackich, Wydawnictwo AGH, Kraków 2010

[23] SohrabiMehran, RiaziMasoud, Jamiolahmady Mahmoud, Brown Christopher, Enhanced Oil Recovery and CO2 Storage by Carbonated Water Injection, IPTC, Doha 7-9 December 2009. 
[24] TalebianSeydeh H., Masoudi Rahim, Tan Isa M., ZithaPacelli, Foam assisted CO2EOR; Concepts, Challenges and Applications, SPE 165280, 2013

[25] Tang, Guo-Qing, Morrow Norman R., Influence of brine composition and fines migration on crude oil/brine/rock interactions and oil recovery, Elsevier, 1999

[26] Zhang, Y., Morrow, N.R., Comparison of Secondary and Tertiary Recovery with Change in Injection Brine Composition for Crude Oil/Sandstone Combinations, SPE 99757, 2006 